\title{
HACIA EL ESPAÑOL: UM LIVRO DE ESPANHOL PARA BRASILEIROS
}

\author{
Terumi Koto Bonnet*
}

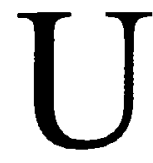

m dos primeiros e principais problemas que o professor de espanhol enfrenta ao iniciar sua carreira é, sem dúvida, a escolha de seu livro de apoio. Há dez ou quinze anos, essa dificuldade consistia em não existir no mercado suficiente variedade que permitisse uma análise comparativa. Há dez ou quinze anos, a essa dificuldade (diga-se de passagem, externa ao professor) somava-se outro problema, o de este não estar preparado para adotar critérios de seleção para suas necessidades específicas.

Atualmente, vários livros de espanhol podem ser encontrados nas livrarias e as licenciaturas em espanhol foram abertas em diversas faculdades, respondendo à demanda criada tanto pela expansão da União Européia que transformou a Espanha na porta de comunicação com a América do Sul, como pela consolidação do Mercosul que abriu um espaço de negociação inédito entre luso-falantes e hispanófonos.

Era inevitável que dadas estas condições favoráveis para a difusão da língua espanhola, houvesse um significativo investimento comercial em termos de publicação de livros didáticos por parte da Espanha, onde paralelamente incrementaram-se estudos sobre a aprendizagem de espanhol como língua estrangeira, doravante referido como ELE.

* Universidade Federal do Paraná 
BONNET, T. K. Hacia el español: um livro de espanhol...

No Brasil, porém, a disponibilização de materiais didáticos e de textos teóricos sobre a aquisição de ELE não parece ter ajudado o professor tanto quanto seria desejável devido a dois fatores não previstos pelos especialistas ibéricos: de um lado, a suposta proximidade interlinguiistica entre o português e o espanhol e, de outro, o questionamento natural sobre as implicações sócio-políticas desse ensino.

Ao publicarem Hacia el español (Saraiva, 1998), CABRAL BRUNO \& MENDOZA demonstraram ter captado e analisado as especificidades lingüísticas e extra-lingüísticas do ensino de espanhol para falantes brasileiros, cujo resultado parece ser a opção por uma noção integradora de aquisição de ELE. Nesta proposta, ter-se-ia como objetivo atingir um bom nível de desempenho lingüístico e pragmático.

Aparentemente o livro segue os mesmos moldes de vários outros livros de espanhol fundamentados nos princípios de metodologia comunicativa, o que implica em organizá-lo em torno de funções comunicativas em contextos sociais definidos pelas necessidades cotidianas (pedidos de informações em várias situações, compras, passeios, reuniões familiares). Para cada unidade temática corresponde, assim, uma função comunicativa, a qual, por sua vez, exige um conhecimento gramatical e lexical capaz de dar conta de sua expressão de forma correta. Para complementar, no final de cada seção existe uma página cultural que informa as produções artísticas em espanhol.

No entanto, para as autoras isso não é suficiente, porque esse material não respeitaria as caraterísticas lingüísticas e socioculturais do aluno brasileiro. Ao conceberem Hacia el español, não escolheram como ponto de partida o objeto a ser aprendido, mas o próprio aprendiz, entendendo que este se engajaria no processo gradual, mas nem sempre linear, de aquisição de língua estrangeira.

A mudança de foco do objeto para o sujeito implica, neste caso, não só em considerar a proximidade entre a língua materna do aluno e a língua a ser aprendida, mas também em analisar cuidadosamente as suas implicações. Não se trataria simplesmente de caraterizar e selecionar os ítens gramaticais mais fáceis ou mais difíceis de serem assimiladas de acordo com o grau de semelhança com a língua materna, como preconiza(va)m os estruturalistas mais tradicionalistas, nem de definir as verdadeiras e falsas semelhanças que podem gerar anedotas mas que pedagogicamente parecem ser inócuas. Tratar-se-ia de estabelecer relações entre os resultados da análise contrastiva entre o português e o espanhol e a organização didática, a partir do suposto de que, apesar das semelhanças nucleares, a língua espanhola constitui-se, para o falante brasileiro, como língua estrangeira.

Assumir a dubiedade de tratar-se de uma língua estrangeira, mas gramaticalmente próxima à língua materna, significa também prever tanto a transferência lingüística propiciando a construção de uma interlíngua popularmente conhecida 
BONNET, T. K. Hacia el español: um livro de espanhol...

como "portunhol", como a sua provável cristalização uma vez satisfeitas as necessidades comunicativas imediatas.

Na literatura especializada, a transferência é entendida como uma estratégia de aprendizagem usada de forma instintiva por aprendizes novatos ${ }^{1}$, valendo-se de seu conhecimento prévio em língua materna, recurso que parece funcionar quando se trata de compreensão, já que se baseia principalmente na exploração de cognatos. No caso de brasileiros aprendendo espanhol, a hipótese de transferência como estratégia parece confirmar-se . Ao ampliar a questão, no entanto, para o nível da produção, o desempenho lingüístico dos alunos brasileiros aponta para a ocorrência de interferência do português na produção em espanhol. Trata-se de textos construídos com as regras da língua materna mas com vocabulário da língua estrangeira.

Por outro lado, dados coletados para diferentes teses e dissertações, como os da citada Durão, sugerem que o processo de aprendizagem de espanhol por falantes brasileiros não segue o desenvolvimento desejado. Esta constatação abre espaço para novos estudos que podem configurar (ou não) o resultado insatisfatório como exemplo de cristalização da interlíngua, ou mais especificamente, como caso de fossilização ${ }^{3}$, entendida como interrupção permanente no processo de aquisição de uma nova gramática.

Conforme especificam no manual do professor, Cabral Bruno \& Mendoza adequaram o conhecimento dessas particularidades à hipótese de Krashen de "input compreensível + 1" para dar conta tanto da recepção de mensagens em espanhol por parte dos lusófonos, como da necessidade de tratar o espanhol como LE, mesmo que o sujeito da aprendizagem seja brasileiro. De acordo com o lingüista americano, o insumo a que é exposto o aluno, deve estar situado num ponto superior ao seu conhecimento imediato, o que lhe exigiria estabelecer uma interação mais constante e cuidadosa com o mesmo.

Nesse sentido, propõem na primeira unidade do nível básico, atividades que introduziriam o aluno brasileiro plenamente no mundo hispânico, em que seria orientado a conversar, inferir, opinar, dramatizar sem temor a erros. As autoras também não temem os erros. Enfatizam que a aprendizagem de uma língua é um processo criativo, e que o erro "es una manifestación de procesos internos que forman parte de la competencia transitoria del alumno".

Assim, esperar-se-ia que o aprendiz brasileiro incrementasse a sua capacidade receptora de mensagens em espanhol, ao mesmo tempo que pudesse compreender e assimilar as novas regras gramaticais sem intermediação da língua materna.

1 Ringbom, 1992.

2 Durão, 1999.

3 Selinker, 1992.

4 Hacia el español, manual do professor: 3. 
BONNET, T. K. Hacia el español: um livro de espanhol...

Entende-se, por conseguinte, que os exercícios de expressão escrita e oral, os diálogos e os textos incluídos em "Hacia el español" sejam relativamente mais longos e complexos que os apresentados em outros livros de espanhol em circulação no mercado brasileiro. Entende-se, principalmente, a finalidade das seções de complementação gramatical fundamentada em análise contrastiva, como sendo a de sistematização dos novos conhecimentos que o aprendiz teria aprendido de forma desigual e desorganizada. Pretendem, assim, que o livro passe a ser um instrumento capaz de acionar, no aluno, um conjunto de estratégias de aprendizagem que lhe permitam aproveitar e otimizar o "input" de tal forma que este possa, sucessivamente, servir de base para novas informações.

A importância do "input" é reforçada na seleção de títulos sugeridos para leitura adicional: são omitidos aqui textos graduados ou adaptados, dando-se preferência a obras literárias hispânicas originais.

Por outro lado, a opção por um "input" original supõe também um contexto sociocultural autêntico, em que sujeitos de carne e osso, historicamente definidos, desenvolvem diálogos reais ou próximos à realidade, e se dispõem a interagir com outros sujeitos, os aprendizes dessa nova língua, também historicamente definidos.

É necessário também lembrar que, quando se trata de ensino de espanhol no Brasil, as considerações de caráter político sempre permeiam a discussão lingüística e pedagógica, sendo um dos pontos aparentemente cruciais, a opção por uma das variantes de espanhol acompanhada de uma justificativa politicamente correta.

Nesse sentido, Cabral Bruno \& Mendoza têm o cuidado de assinalar, em primeiro lugar, que o "input" lingüístico e cultural não deve se tornar uma camisa de força que reprima a identidade brasileira. Pretendem que o aluno se integre ao mundo hispânico "a través de su propia expresión", , e que nesse processo aprenda também a (re) conhecer o discurso do outro.

Em segundo lugar, ao privilegiarem textos de autores hispano-americanos, sugerem a importância desse tipo de "input" para o aluno brasileiro, revelando, assim, a sua própria opção ideológica, o que iria em contramão ao título do livro, "Hacia el español", que aponta para uma abordagem puramente linguística do ensino de espanhol, sem preocupação com o sujeito cultural dessa aprendizagem. Na realidade, as autoras tentam conciliar a questão do ensino de ELE, conforme o padrão espanhol, com as particularidades de ensino de ELE no Brasil, tomando como base duas variantes de espanhol, o peninsular e o americano, para permitir ao aluno o contato inicial com a totalidade do mundo hispânico.

Consideradas as duas faces da moeda (questões lingüísticas c políticas do

5 op. cit.:3. 
BONNET, T. K. Hacia el español: um livro de espanhol...

ensino de espanhol aos falantes brasileiros), "Hacia el español" parece satisfazer as necessidades práticas e imediatas do aluno e do professor como sujeitos implicados diretamente no processo de ensino/aprendizagem de espanhol, em que se aproximam de uma língua e cultura estrangeira semelhante à sua.

Nesta relação de (re)conhecimento de regras gramaticais e de valores culturais, as autoras parecem esperar, acima de tudo, que a identidade nacional seja (re)discutida para permitir uma integração ibero-americana consciente e expressa de forma lingüisticamente correta.

É possível, no entanto, que, por falta de uma literatura especializada em variação lingüística do espanhol relacionada às questões didáticas, o tratamento superficial dado aos diversos textos hispânicos, em que a sua exploração se limita à apresentação de um determinado léxico, abre espaço à tradicional pergunta de o que fazer com toda essa variedade regional, o que reconduz ao círculo vicioso de qual seria a abordagem mais adequada de ELE quando se trata de falantes brasileiros. Neste caso especifico, nem sequer a intenção de criar um material que supere as fronteiras linguiísticas regionais, capaz de evitar qualquer tipo de preconceito contra alguma variante, parece ser suficiente, já que uma mera exposição maciça e indiscriminada ao texto autêntico não garantiria seu real aproveitamento.

Louve-se, porém, a iniciativa de elaborar um material didático fundamentado em estudos de aquisição de língua estrangeira, que, por isso mesmo, mudou o foco de interesse, do objeto a ser estudado para o sujeito que estuda, e que incorpora o aspecto cultural na aprendizagem de ELE de uma forma tal que permite, pelo menos, a sensibilização do aluno brasileiro pelo mundo hispânico.

\section{REFERÊNCIAS}

CABRAL BRUNO, F.T. ; MENDOZA, M.A. Hacia el español. São Paulo: Saraiva, 1998.

COADY, J. L2 vocabulary acquisition through extensive reading.In: COADY, J.; HUCKIN, T. Second Language Vocabulary Acquisition. Cambridge, Cambridge: University Press, 1997.

DURÃO, B. de A. B. Análisis de errores e interlengua de brasileños aprendices de español y de españoles aprendices de portugués. Londrina: UEL, 1999.

RINGBOM, H. On L1 transfer in L2 comprehension and L2 production. Language Learning. Michigan: Michigan University Press, 1992 v. 42, n.1, p.85-112.

SELINKER, L. Rediscovering Interlanguage. Londres, Longman, 1992.

6 Coady, 1997. 